\title{
Knowledge framework and emerging trends in intracranial aneurysm magnetic resonance angiography: a scientometric analysis from 2004 to 2020
}

\author{
Jiazhen Zheng ${ }^{1 \#}$, Rui Zhou ${ }^{1 \#}$, Bingyao Meng ${ }^{2 \#}$, Furong Li ${ }^{1}$, Huamin Liu ${ }^{1}$, Xianbo Wu ${ }^{1}$ \\ ${ }^{1}$ Department of Epidemiology, School of Public Health (Guangdong Provincial Key Laboratory of Tropical Disease Research), Southern Medical \\ University, Guangzhou, China; ${ }^{2}$ Department of Radiology, School of Public Health (Guangdong Provincial Key Laboratory of Tropical Disease \\ Research), Southern Medical University, Guangzhou, China
}

"These authors contributed equally to this work.

Correspondence to: Xianbo Wu. Department of Epidemiology, School of Public Health (Guangdong Provincial Key Laboratory of Tropical Disease Research), Southern Medical University, No. 1838 Guangzhou Avenue North, Guangzhou 510515, China. Email: wuxb1010@smu.edu.cn.

Background: As magnetic resonance angiography (MRA) has been increasingly used in the follow-up of intracranial aneurysms (IAs) as a non-invasive technique, the knowledge framework and areas of research interest in intracranial aneurysms magnetic resonance angiography (IAMRA) change approximately every 10 years. However, few studies have quantitatively analyzed the published literature in this field. In the present study, we used scientometrics to survey the knowledge field, development trends, and research focus of IAMRA with the aim of providing a reference for further study.

Methods: We collected articles on IAMRA published from 2004 (Jan 1, 2004) to 2020 (May 24, 2020). Web of Science Core Collection databases (WoSCCd) including the Science Citation Index Expanded were searched. An experienced staff member from the Department of Radiology at Southern Medical University, assisted in screening articles for relevant articles. We used ArcGIS (a mapping and location analytics platform) to perform geographic visualization. Excel 2016 was used to analyze the literature data, including number of publications, impact factor (IF), and publication year. CiteSpace $V$ was used to conduct a series of literature feature clustering, including author co-citation analysis, reference co-citation analysis (RCA), and burst keywords analysis.

Results: A total of 1,272 articles on IAMRA published between 2004 and 2020 were included. Of 257 journals, American Fournal of Neuroradiology (IF 2018: 3.256) published the most IAMRA articles (109 publications, 8.57\%), followed by Fournal of Neurosurgery (IF 2018: 4.131, 51 publications, 4.16\%), and Neuroradiology (IF 2018: 2.504, 51 publications, 4.01\%). Of 56 countries, the USA published the most, with 347 articles [27.28\%, IF: 3.14 (average IF of all journals in the country)], followed by Japan (242 articles, 19.03\%, IF: 2.38), Germany (135 articles, 10.61\%, IF: 3.21), and China (101 articles, 7.94\%, IF: 2.86). A total of 1387 institutions published articles, with the Mayo Clinic publishing the most (33 articles, 2.59\%), followed by Shanghai Jiao Tong University (25 article, 1.97\%), Seoul National University (23 articles, 1.81\%), and University Medical Center Utrecht (19 articles, 1.49\%). Of 399 authors, Rinkel ranked first with 19 articles, followed by Li MH (18 articles), Uchino A (15 articles), and Saito N (13 articles). Cluster RCA showed that the first cluster was "\#0 growth", followed by "\#1 Guglielmi detachable coils". Timeline views showed that the time span of "\#0 growth" was the closest to today. The modularity value was 0.6971 , and the mean silhouette value was 0.5477 . According to the burst keyword analysis, "risk factors associated to rupture" was the topic with the strongest burst since 2017. Studies conducted in several countries suggested that age is inversely related to the risk of rupture, which implies the importance of MRA follow-up for patients of different age.

Conclusions: From 2004 to 2020, the number of published IAMRA-related articles gradually increased. 
The USA and Western Europe lead in the field, with a concentration of cutting-edge talents and highlevel scientific research institutions. A synthesis of the clustering results of RCA and burst keyword analysis indicated that unruptured IA growth, stent-assisted coil embolization, and risk factors associated to rupture were the current hotspots in IAMRA research.

Keywords: Intracranial aneurysms (IA); magnetic resonance angiography (MRA); bibliometrics; CiteSpace; cocitation analysis

Submitted Jun 04, 2020. Accepted for publication Nov 24, 2020.

doi: 10.21037/qims-20-729

View this article at: http://dx.doi.org/10.21037/qims-20-729

\section{Introduction}

Intracranial aneurysm (IA), a vascular disorder that involves a cystic protuberance caused by local thinning of the vascular wall, mainly manifests as localized dilations of the cerebral artery wall that are prone to rupture and subsequent bleeding (1). IAs are commonly acquired lesions that occur in $2-3.2 \%$ of the general population and account for about $85 \%$ of subarachnoid hemorrhages (SAH), making IAs the leading cause of hemorrhagic stroke $(2,3)$. Approximately $12 \%$ of patients with ruptured IAs die before reaching hospital, and about $30 \%$ of hospitalized patients die within 1 month after their first rupture and bleeding event (4-6). Of those who survive, 30\% will be left severely impaired and suffer from permanent neurological deficits (7). Residual and recurrent IAs have a rebleeding incidence as high as $30 \%$, which results in significant rates of morbidity and mortality $(8,9)$. Therefore, early diagnosis and periodic reexamination are critical.

In clinical practice, digital subtraction angiography (DSA) remains the gold standard test for the diagnosis of aneurysm recurrence. DSA is an invasive imaging technique with associated risks, including ionizing radiation exposure, nephrotoxicity from iodine-based contrast agents, cerebral thromboembolism, iatrogenic arterial damage, and neurological complications $(10,11)$. Magnetic resonance angiography (MRA) has been used in the followup of IAs, as it is a non-invasive technique and reduces some of the risks associated with serial DSA examinations (12-15). In their research, van Amerongen et al. and Menke et al. discovered that MRA has a moderate-to-high diagnostic performance when compared with DSA $(16,17)$. The diagnostic performance of MRA techniques have been assessed in previous meta-analyses, demonstrating its reliability, especially for aneurysms treated using endovascular techniques (18). In addition, MRA has the advantages of not requiring intravenous contrast agent administration and being relatively less costly (19).

Despite the vast number of articles being published on MRA application for cerebral aneurysm examinations over the past decade, the systematic collation and scientific analysis of this literature are lacking. CiteSpace is a useful tool for bibliometric visualization (20), which focuses on finding critical points in the development of a field or domain, especially turning points and pivotal points. Using CiteSpace, any aspect of the literature can be visualized, including geospatial patterns of collaboration and cocitation $(20,21)$.

As intracranial aneurysms magnetic resonance angiography (IAMRA) is a technique that is increasingly being used by neurointerventionalists, we aimed to construct the knowledge framework of IAMRA and explore the research areas of interest in this domain by systematically analyzing the relevant research published from 2004 to 2020 .

\section{Methods}

\section{Data collection}

Web of Science Core Collection databases (WoSCCd) is a complete scientific literature database that is used by researchers in various domains, including bibliometrics (22-27). On May 24, 2020, we retrieved all the literature on IAMRA published on WoSCCd between 2004 and 2020 through. To avoid publication date bias, we performed all searches on the same day.

The Science Citation Index Expanded (SCIE) was selected for the search. The search statements used to search the literature from 2004 to 2020 were as follows: TS=(("cerebral aneurysm*" OR "intracranial aneurysm*" OR "berry aneurysm*” OR "basilar artery aneurysm*”) OR (("aneurysm*”) AND ("cerebr"” OR "subarachnoid*” OR "brain*” OR “intracranial*”))) AND TS=(“MRA*” 


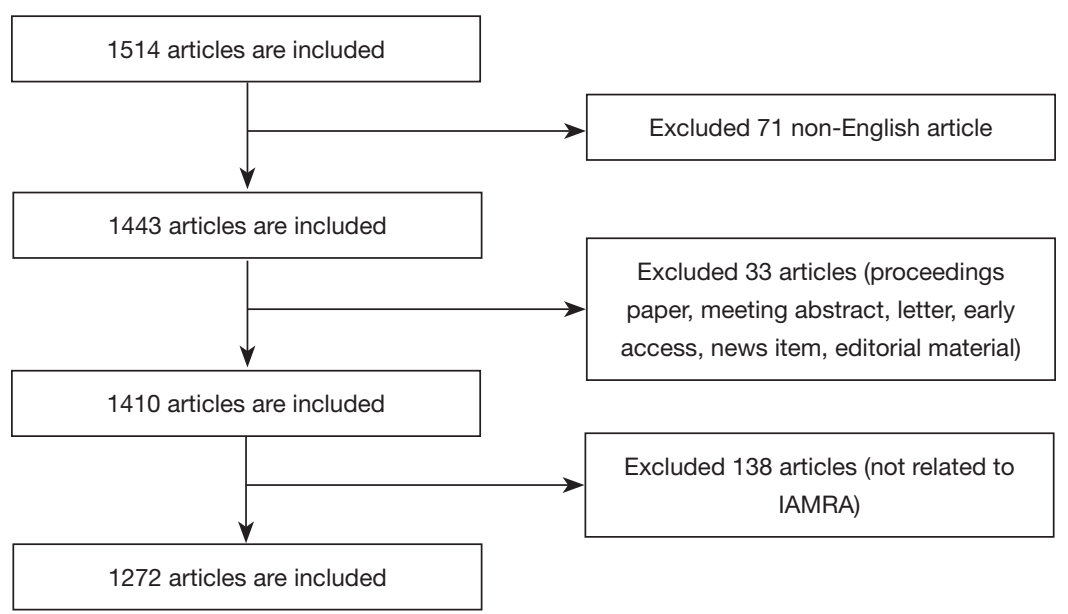

Figure 1 Flowchart for inclusion and exclusion of IAMRA articles. IAMRA, intracranial aneurysms magnetic resonance angiography.

OR "magnetic resonance angiography*" OR "MR angiography") AND Language= English AND Document type $=($ Article OR Review) .

As performed in a previous study, the literature feature clustering in the present study included the title, abstract, keywords, source publication, authors' names, institutions and countries, year of publication, and references (22). Raw data were downloaded from WoSCCd in full-record, plaintext format. In the present study, 2 reviewers assessed the downloaded documents and excluded those unrelated to IAMRA; a third reviewer was used if a consensus between the 2 reviewers could not be reached. The process of inclusion and exclusion is shown in Figure 1. Ethical approval and informed consent were not applicable in the present study.

\section{Statistical and plotting process}

The included literatures were systematically analyzed by Excel 2016 and CiteSpace V (Drexel University, Philadelphia, USA). We used Excel 2016 and GraphPad Prism 8 (University of California San Diego, San Diego, USA) to display the trend in the number of articles published by year and the distribution of articles by journal. ArcGIS was used to draw the heatmap of the top 10 countries' total number of published articles between 2004 and 2020 and their average impact factor (IF). CiteSpace V was used to perform a co-occurrence analysis and visualize the collaboration networks of the authors/institutes/ countries/keywords. Author co-citation analysis (ACA) and reference co-citation analysis (RCA) were also performed using CiteSpace V, and a related knowledge framework was constructed. Burst keyword detection was also performed to investigate recurrent new keywords. The 50 most cited or found articles were selected to create the individual network in a 1-year interval. Moreover, log-likelihood ratio weighting was used to analyze the contents of each cluster $(20,21)$.

\section{Results}

\section{Publication year}

From Jan 1, 2004 to May 24, 2020, 1,272 articles met the criteria for inclusion. The number of articles published in different years is shown in Figure 2, which indicates a consistently increasing trend from 2004 (52 articles) to 2014 (101 articles) before the number appears to plateau.

\section{Analysis of journals}

A total of 257 academic journals published articles on IAMRA. The top 10 most prolific journals are listed in Table 1. Of the top 10 journals, 6 were from the USA. American Fournal of Neuroradiology (IF 2018: 3.256) published the most (109 publications, $8.57 \%$ ), followed by fournal of Neurosurgery (IF 2018: 4.131, 51 publications, 4.01\%) and Neuroradiology (IF 2018: 2.504, 50 publications, 3.93\%).

\section{Analysis of countries and institutes}

From Jan 1, 2004 to May 24, 2020, a total of 1,272 papers were published in 56 countries. The top 10 countries are shown in Table 2 and Figure 3. The USA ranked first with 347 articles (27.28\%, IF: 3.14), followed by Japan 
(242 articles, 19.03\%, IF: 2.38), Germany (135 articles, 10.61\%, IF: 3.21), and China (101 articles, 7.94\%, IF: 2.86), accounting for $64.86 \%$ of the total. Articles published in the Netherlands had the highest average IF (IF 2018: 5.07), followed by the UK (IF 2018: 4.09), Canada (IF 2018: 3.95), and France (IF 2018: 3.54). Centrality and cited half-life are also shown in Table 2.

A total of 1387 institutes published articles in the field of IAMRA. The Mayo Clinic published the most (33 articles, $2.59 \%$ ), followed by Shanghai Jiao Tong University (25 articles, $1.97 \%$ ), Seoul National University (23 articles, $1.81 \%$ ), and University Medical Center Utrecht (19 articles, $1.49 \%)$. The average IF of the articles published by the

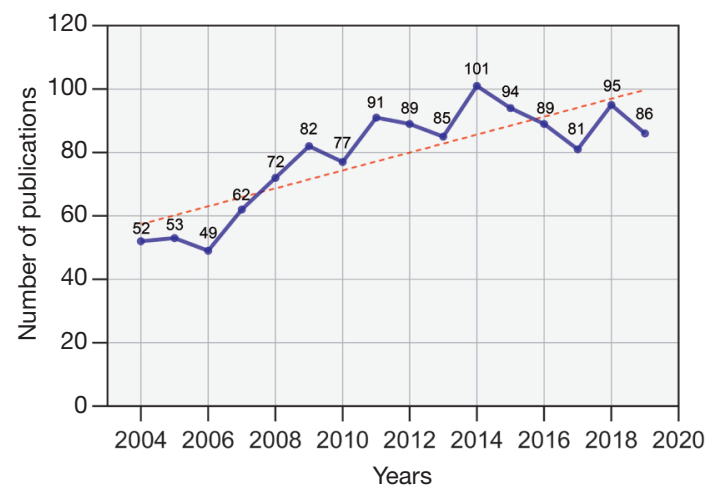

Figure 2 Number of articles published annually in the IAMRA field from 2004 to 2019. (The number of papers collected in 2020 is incomplete, with a total of 26 as of retrieval time). IAMRA, intracranial aneurysms magnetic resonance angiography.
University Medical Center Utrecht was the highest at 8.437. The second highest was that of the University of Cincinnati (IF 2018: 5.608), followed by the Mayo Clinic (IF 2018: 4.302).

\section{Analysis of autbors}

More than 399 authors published articles in the field of IAMRA. Rinkel GJE ranks first with 19 articles, followed by Li MH (18 articles), Uchino A (15 articles), Saito N (13 articles), etc. (Table 3). The co-authorship among these representative authors is shown in Figure 4.

ACA is the frequency of authors' co-citation (when articles from 2 different authors are each cited by a third author in a single work) to explain the academic relationship between core authors (Figure 5). More than 372 authors were co-cited in articles on IAMRA. Of the top 10 co-cited authors, Wiebers D (175 times) was co-cited the most, followed by White PM (148 times), Raymond J (148 times), and Molyneux A (144 times) (Table 3).

\section{Analysis of reference citations and co-citations}

RCA uses literature as the element of analysis, and can reflect the relationship between the literature by analyzing patterns and trends in co-citation. The top 10 cited articles are listed in Table 3. The mapping of knowledge domains and timeline views constructed by RCA are shown in Figures 6 and 7. In Figure 6, literature on IAMRA published from 2004 to 2020 can be clustered into 8 research areas of interest. Clusters are ordered by numbers from small

Table 1 Top 10 journals according to number of articles published in the IAMRA field from 2004 to 2020

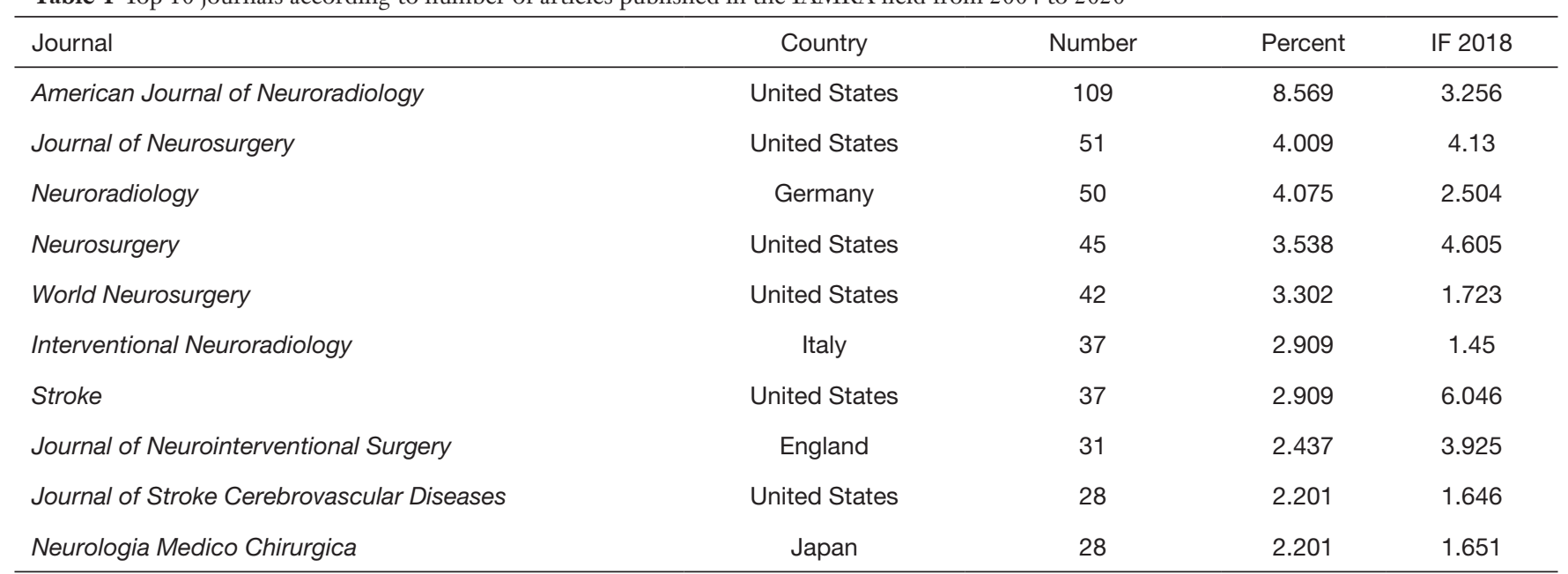

IAMRA, intracranial aneurysms magnetic resonance angiography. 
Table 2 Top 10 countries and institutions according to the number of articles published in the IAMRA field from 2004 to 2020

\begin{tabular}{|c|c|c|c|c|c|c|c|c|c|c|}
\hline Rank & Country & Counts (\%) & Average IF & Centrality $^{\dagger}$ & Half-life & Institution & Counts (\%) & Average IF & Centrality & Half-life \\
\hline 2 & Japan & $242(19.03)$ & 2.38 & 0 & 9 & $\begin{array}{c}\text { Shanghai Jiao Tong } \\
\text { University }\end{array}$ & $25(1.97)$ & 3.964 & 0 & 4 \\
\hline 3 & Germany & $135(10.61)$ & 3.21 & 0.33 & 9 & Seoul Natl Univ & $23(1.81)$ & 2.892 & 0 & 3 \\
\hline 6 & France & $74(5.82)$ & 3.54 & 0.13 & 8 & Univ Calif San Francisco & $17(1.34)$ & 3.781 & 0.02 & 2 \\
\hline 7 & The Netherlands & $56(4.40)$ & 5.07 & 0.14 & 7 & Saitama Med Univ & $16(1.26)$ & 1.538 & 0.04 & 4 \\
\hline 8 & Canada & $38(2.99)$ & 3.95 & 0.02 & 5 & Univ Hosp Essen & $16(1.26)$ & 3.438 & 0.05 & 1 \\
\hline
\end{tabular}

${ }^{\dagger}$, an index used to quantify the importance of points in the network. Value of centrality is proportional to the mediating effect half-life; that is, the number of years in which an organization's forward calculated citations from the current year account for $50 \%$ of the total citations. IF, impactor factor (Journal Citation Reports 2018, released on June 6, 2019). IAMRA, intracranial aneurysms magnetic resonance angiography.

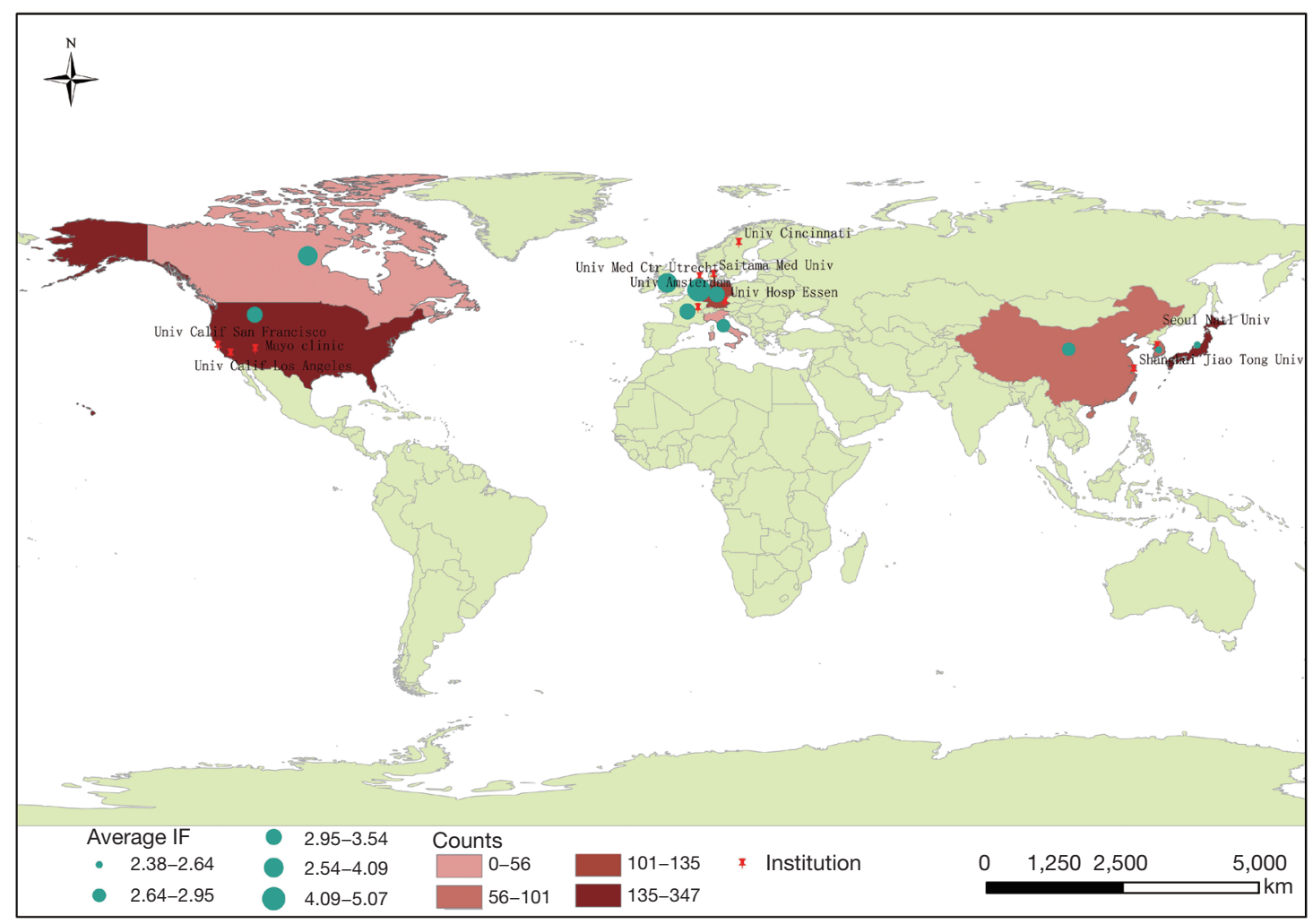

Figure 3 Heat map of the total number of articles on IAMRA published by the top 10 countries between 2004 and 2020 and their average impact factor (IF). The map also shows the top 10 institutions according to articles published. IAMRA, intracranial aneurysms magnetic resonance angiography. 
Table 3 Top 10 most published authors and most co-cited references in the IAMRA field from 2004 to 2020

\begin{tabular}{lcccccc}
\hline Rank & Author & Count & Co-cited author & Counts & Count \\
\hline 1 & Rinkel GJE & 19 & Wiebers D & 175 & Molyneux A, 2002, Lancet, volume 360, page 1267 \\
2 & Li MH & 18 & White PM & 148 & Raymond J, 2003, Stroke, volume 34, page 1398 \\
3 & Uchino A & 15 & Raymond J & 148 & Vlak MHM, 2011, Lancet Neurol, volume 10, page 626 & 57 \\
4 & Saito N & 13 & Molyneux A & 144 & Wiebers D, 2003, Lancet, volume 362, page 103 \\
5 & Velthuis BK & 12 & Molyneux AJ & 138 & Molyneux AJ, 2005, Lancet, volume 366, page 809 \\
6 & Li YD & 12 & Pierot L & 120 & Majoie C, 2005, Am J Neuroradiol, volume 26, page 1349 & 55 \\
7 & Huston J & 10 & Cloft HJ & 108 & Morita A, 2012, New Engl J Med, volume 366, page 2474 \\
8 & Brinjikji W & 9 & Schievink WI & 107 & Yamada N, 2004, Am J Neuroradiol, volume 25, page 1154 & 49 \\
9 & Kang HS & 9 & Juvela S & 103 & Pierot L, 2006, Am J Neuroradiol, volume 27, page 744 & 40 \\
10 & Han MH & 9 & Anzalone N & 98 & Willinsky RA, 2003, Radiology, volume 227, page 522 & 40 \\
\hline
\end{tabular}

IAMRA, intracranial aneurysms magnetic resonance angiography.

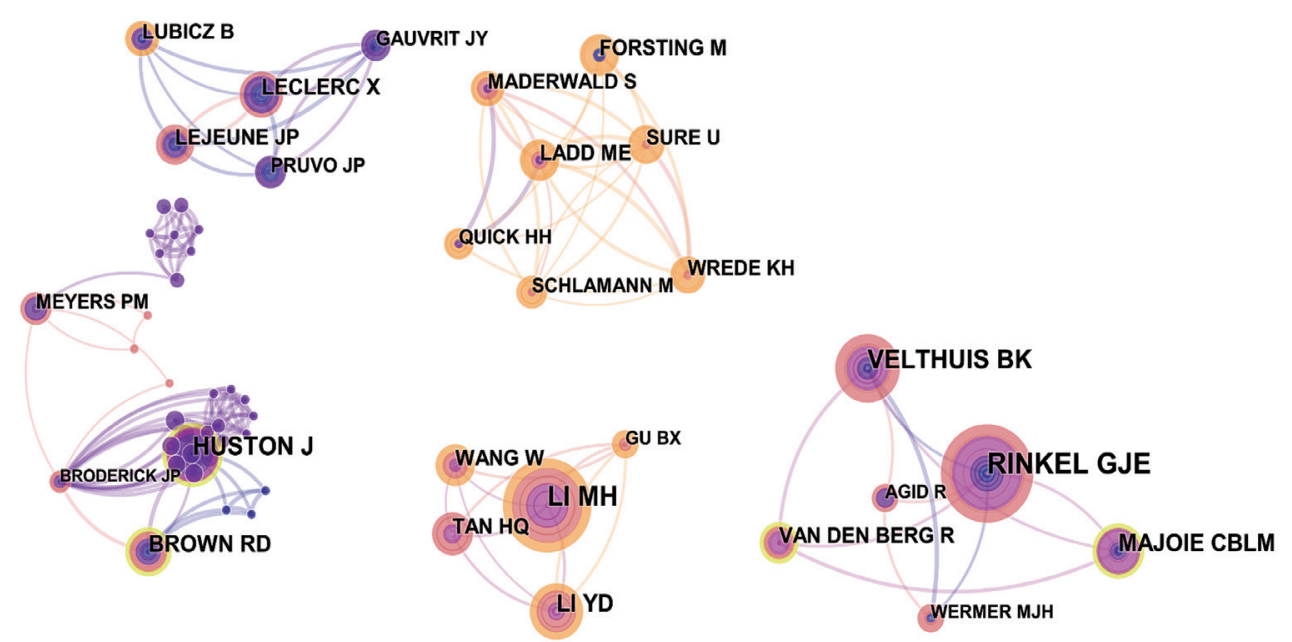

Figure 4 Map of active authors and their co-authorship in the IAMRA field since 2004. Links between authors represent their coauthorship, the size of circles represents the counts of author articles, and the color of circles and the links between them reflect the occurrence time. The brighter they are, the more recently they occurred. Only authors with more than 5 articles are shown. IAMRA, intracranial aneurysms magnetic resonance angiography.

to large according to the number of article co-citations. The first cluster is "\#0 growth", followed by "\#1 Guglielmi detachable coils (GDCs)". Timeline view shows that the time span of "\#0 growth" is the closest to today. The modularity value $(\mathrm{Q})$ is 0.6971 , and the mean silhouette value $(\mathrm{S})$ is 0.5477 . $\mathrm{Q}>0.3$ means that the community structure is significant; when the $\mathrm{S}>0.5$, clustering is efficient and convincing.

\section{Analysis of keyword burst}

A total of 292 keywords were detected in the analysis of the cited literature. The top 50 keywords are presented in Figure 8, which are sorted by the year beginning the burst. The appearance time points, burst strength, and time span of the burst keywords varied. From 2004 to 2020, the highest-strength burst keyword was 


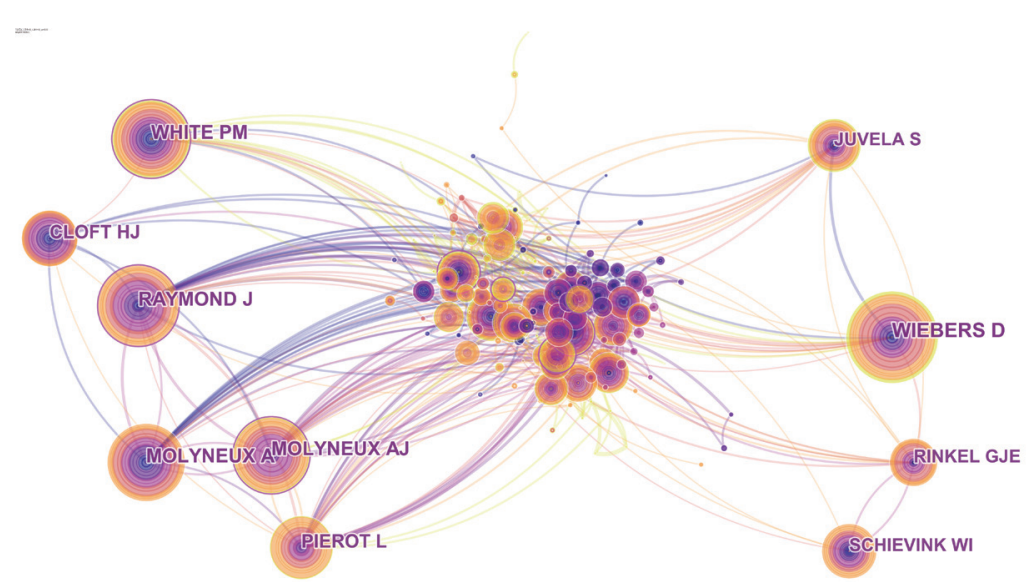

Figure 5 Map of author co-citation networks in the IAMRA field since 2004. The size of circles represents the co-citation number of authors. Links between nodes reflect the co-citation of authors, and the thickness of the links represent the intensity of the co-citation. Only authors with more than 95 co-citations are shown. IAMRA, intracranial aneurysms magnetic resonance angiography.

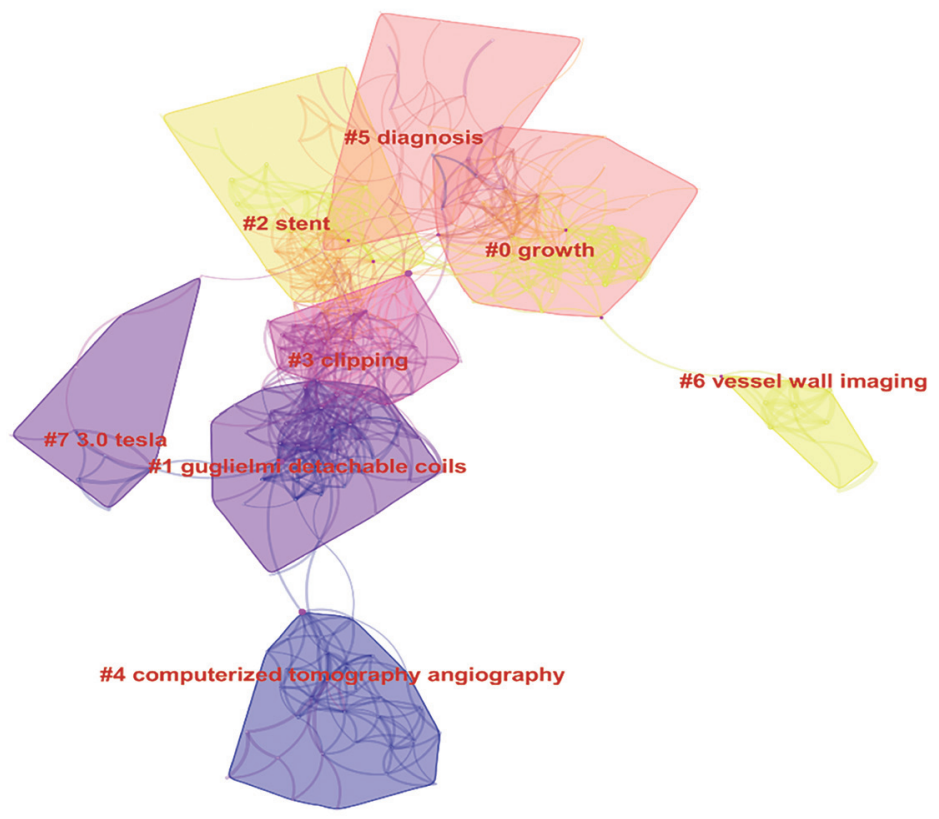

Figure 6 Cluster analysis chart of RCA in the IAMRA field since 2004. The network has been divided into 8 co-citation clusters, and red letters represent the name of clusters. The number of nodes covered by each convex hull represents the number of cited articles in this field. Links between nodes reflect the co-citation of the articles. The brighter the convex hull and links are, the more recently they appeared. IAMRA, intracranial aneurysms magnetic resonance angiography.

"International Subarachnoid Aneurysm Trial (ISAT)" (7.739). "Risk factor", "association", and "rupture" were the keywords with the 3 highest burst strengths within the past 3 years, with burst strengths of 5.32, 4.33, and 4.21, respectively.

\section{Discussion}

\section{General information}

We found a growing trend in the number of IAMRA articles published from 2004 to 2020, with an increase from 


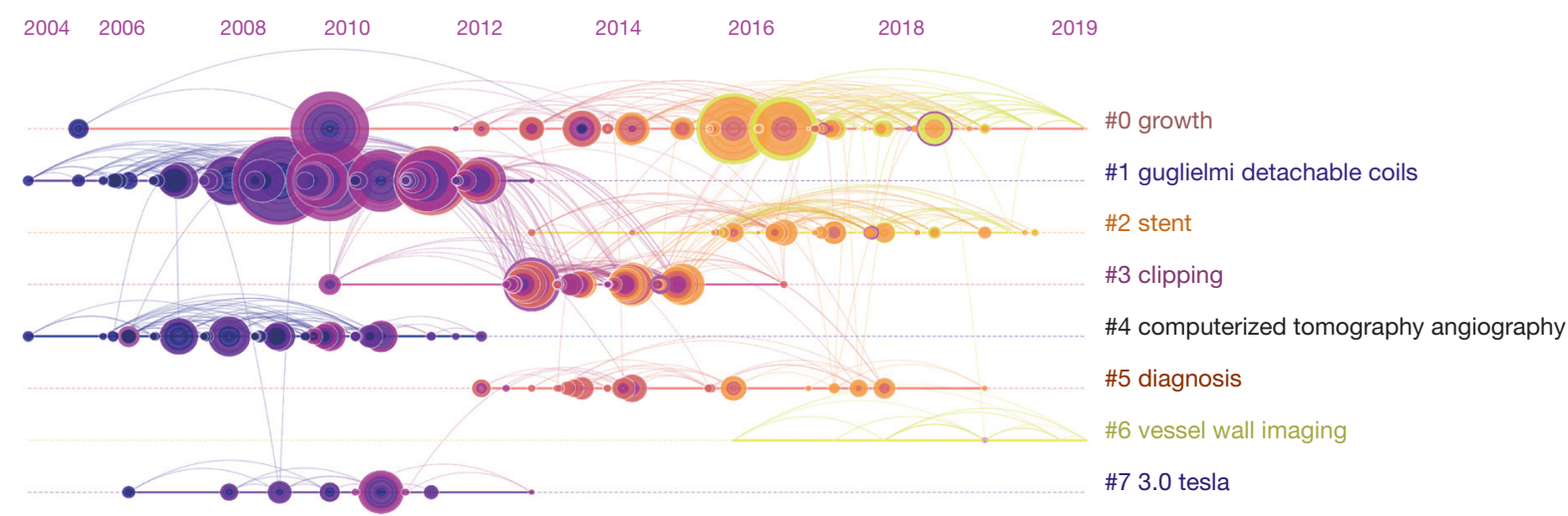

Figure 7 Timeline view of RCA in the IAMRA field since 2004. The emergence time point and time span of 10 clusters are shown. RCA, reference co-citation analysis; IAMRA, intracranial aneurysms magnetic resonance angiography.

52 articles in 2004 to 101 articles in 2014, followed by a plateau, and a climb to 86 articles in 2019. This gradual increase may be a result of the emergence of new and advanced MRA technologies in the past decade, which have increased the reliability in the detection of residual aneurysms after endovascular treatment. In addition, MRA has lower risk of radiation exposure, contrast materialinduced complications, hematoma on the puncture site, and risk of neurologic complications due to thromboembolism or arterial dissection compared with DSA examinations (15).

The top 10 journals published 458 articles, accounting for $37.3 \%$ of the total, which indicates a significant contribution in the IAMRA domain. In addition, a large proportion of IAMRA-related literature was published by journals in the neuroradiology and neurosurgery domains. These data can be used as a reference for future researchers to quote and publish articles in the IAMRA domain.

\section{Distribution information}

Among the top 10 contributing countries or regions, the USA was the main collaborator with other countries (centrality: 0.75), and published the most articles in the domain of IAMRA, followed by Western Europe and East Asia. A multitude of neuroradiology research centers and multicenter medical centers distributed throughout the USA provide the bulk of aneurysm image samples for imaging research. Journals from the Netherlands had the highest average IF (5.07), which indicates its high level of IAMRA research. This result can be attributed to the welldeveloped medical device industry of the Netherlands, with IMRA-related equipment such as the angiography suite
Azurion (Philips, Amsterdam, the Netherlands) being used to integrate angiography simulations (28).

The distribution of literature by institution is similar to that by country. The Mayo Clinic, where neuroradiology originated as a subspecialty 90 years ago, ranks high in the number of published articles, centrality, and IF. After a long-term development, the Mayo Clinic has gradually attracted the top talents in the neuroradiology field and achieved numerous technological breakthroughs, especially in specialized MRA radiographic equipment (29).

From 2004 to 2020 , all of the top 10 most prolific authors published more than 9 articles, and the top 10 cited authors were co-cited in IAMRA domain at least 98 times. However, as shown in Table 3, none of the top 10 most prolific authors placed in the most co-cited authors list, suggesting that articles published by the most productive authors are not necessarily articles of high quality, as the number of article co-citations is generally considered as an indicator of academic merit. Based on a cohort with 2,143 patients with ruptured IAs, Molyneux et al. published an article on the International Subarachnoid Aneurysm Trial (ISAT) in Lancet, which was the most co-cited paper on IAMRA (69 times) from 2004 to 2020, providing an informative and credible reference to the IAMRA knowledge network (30).

For co-authorship, core authors in the IAMRA domain can be divided into 5 academic groups (Figure 4), in which authors work hand in hand and frequently participate in academic exchange. Of the 5 academic groups, 3 have a clear central member, with Huston J (from the Department of Diagnostic Radiology, Mayo Clinic and Foundation), Li $\mathrm{MH}$ (from the Institute of Diagnostic and Interventional 


\begin{tabular}{|c|c|c|c|}
\hline Keywords & Year $S$ & trength Begin End & $2004-2019$ \\
\hline cerebral arteriovenous malformation & 2004 & 6.110420042007 & \\
\hline computed tomographic angiography & 2004 & 5.95620042009 & \\
\hline flight mr angiography & 2004 & 5.422820042006 & \\
\hline computerized tomography angiography & 2004 & 4.579620042007 & \\
\hline diagnosis & 2004 & 4.001520042005 & \\
\hline magnetic resonanceangiography & 2004 & 2.879320042008 & \\
\hline saccular aneurysm & 2004 & 7.03320052009 & \\
\hline time of flight & 2004 & 4.862420052007 & \\
\hline guglielmi detachable coil & 2004 & 6.161420062012 & \\
\hline conventional angiography & 2004 & 4.082420062010 & \\
\hline trial isat & 2004 & 7.73920072012 & \\
\hline ruptured intracranial aneurysm & 2004 & 5.471620072012 & \\
\hline contrast & 2004 & 3.659320072009 & \\
\hline single center experience & 2004 & 3.160620072010 & \\
\hline sense & 2004 & 2.857120072008 & \\
\hline enhanced $\mathrm{mr}$ angiography & 2004 & 4.863120082012 & \\
\hline outem & 2004 & 4.503920082010 & \\
\hline cerebral angiography & 2004 & 4.456820082012 & \\
\hline experience & 2004 & 3.696920082009 & \\
\hline model & 2004 & 3.324920082009 & \\
\hline digital subtraction angiography & 2004 & 3.437120092010 & \\
\hline retreatment & 2004 & 4.934520102012 & \\
\hline cerebralaneurysm & 2004 & 2.910320102013 & \\
\hline trial & 2004 & 3.204320112013 & \\
\hline accuracy & 2004 & 3.010120122013 & \\
\hline magnetic resonance imaging & 2004 & 2.887220122014 & \\
\hline of the literature & 2004 & 6.028920132015 & \\
\hline safety & 2004 & 3.811720132015 & \\
\hline unruptured intracranial aneurysm & 2004 & 3.147620132016 & \\
\hline complication & 2004 & 2.932520132014 & \\
\hline metaanalysis & 2004 & 6.812320142019 & \\
\hline anatomy & 2004 & 5.660820142016 & \\
\hline moyamoya disease & 2004 & 4.315320142019 & \\
\hline term follow up & 2004 & 3.271220142015 & \\
\hline cerebral artery & 2004 & 3.032320142015 & \\
\hline anterior cerebral artery & 2004 & 2.945620142015 & \\
\hline microsurgical anatomy & 2004 & 2.853520142016 & 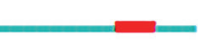 \\
\hline flow diverter & 2004 & 2.947520152017 & \\
\hline frequency & 2004 & 2.947520152017 & \\
\hline vascular disord & 2004 & 7.374420162019 & \\
\hline flow & 2004 & 4.851820162019 & \\
\hline stent & 2004 & 4.762620162019 & \\
\hline prevalence & 2004 & 4.095820162017 & \\
\hline blood flow & 2004 & 3.110620162019 & 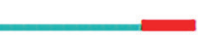 \\
\hline risk factor & 2004 & 5.315220172019 & - \\
\hline association & 2004 & 4.334320172019 & \\
\hline rupture & 2004 & 4.211720172019 & - \\
\hline pipeline embolization device & 2004 & 3.882120172019 & \\
\hline dsa & 2004 & 3.184520172019 & \\
\hline coiling & 2004 & 3.182720172019 & \\
\hline
\end{tabular}

Figure 8 The top 50 keywords with the strongest citation bursts in the IAMRA field. The green line represents time period from 2004 to 2019, and the red line represents the time span of the burst. IAMRA, intracranial aneurysms magnetic resonance angiography. 
Radiology, Shanghai Jiao Tong University), and Rinkel GJE (Department of Neurology and Neurosurgery, Brain Center Rudolf Magnus, University Medical Center Utrecht, Utrecht University) being the keystone researchers in their respective groups. The 3 authors are well known in the IAMRA domain and all have conducted research that relates to the assessment of the diagnostic value of MRA in patients with IAs at different ages and with different physical conditions (31-33).

The extent of co-citation between authors has a positive correlation with the similarity of authors' research domains, and ACA is a useful way to analyze this relationship. According to this method, we classified and represented author co-citations graphically to identify the core authors and to analyze the relationship between authors in a specific field. The map of the author co-citation networks revealed that the highly co-cited authors can be divided into 2 groups (Figure 5). Researchers can identify authors with a similar specialism in the IAMRA domain by using the ACA map.

\section{Research areas of interest}

CiteSpace software includes RCA (20), which offers an informative snapshot of the network of articles and the professional domain that numerous co-cited articles converge in. The cluster analysis of various co-citation areas can accurately identify research areas of interest (34). The key to identifying the central issue in the academic domain is to analyze the numeric value of cluster names by synthesizing the information of the cluster analysis chart and the timeline view (Figures 6 and 7). Using this, it was reasonable to conclude that "\#0 growth", "\#1 GDCs", and "\#2 stent" were the research areas of interest in recent years, as their clusters contain relatively more nodes and have a comparatively more recent occurrence time.

Growth refers to unruptured IA growth. Previous studies have reported that approximately 10\% of unruptured IAs grow during the process of follow-up angiographic imaging (35). Due to the instability in growing aneurysms (36), aneurysm growth is closely related to the risk of rupture and is known to cause severe socioeconomic burden (37-42). As MRA is safe, non-invasive, and accurate, it plays an important role in morphological follow-up examinations of unruptured IA growth. As reported in Jin et al.'s meta-analysis (43), MRA was used in 14 of 23 studies of aneurysm growth. The metaanalysis questions if it is reasonable to conduct serial MRA from a pathophysiological angle. Small unruptured IAs take time to grow, and the incidence of growth is higher than that of rupture in this specific time $(31,44)$, suggesting there may be a therapeutic time window to detect enlargement before rupture; therefore, serial MRA followed-up is necessary in the treatment of unruptured IAs. This was demonstrated in Matsumoto et al.'s study, in which MRA was found to reduce the risk of mortality of growing unruptured IAs, especially within 1 year and in patients with multiple aneurysms (45). Although progress been made in the research of MRA application in growing unruptured IAs, several important obstacles remain. First, treatment decisions are not currently based on recognized criteria or parameters, but rather an individual appreciation of anatomical features, such as size and location. These provide an incomplete assessment of rupture risk (46). After reviewing the literature, we found that the majority of studies defined IA growth as an increase of $>1 \mathrm{~mm}(45,47-55)$, although some studies used a definition of either a $1.5 \times$ increase of diameter $(56,57)$, or $>2 \mathrm{~mm}$ increase (58-60). This variability between studies inevitably leads to a serious risk of bias. We thus recommend a subgroup analysis be performed to identify differences based on the definition of IA growth. Second, IA growth may occur before rupture. However, this may be difficult detect due to the long interval between follow-up examinations, leading to an underestimation of the rupture risk in patients with aneurysm growth. Therefore, it is important to have an optimum interval between MRA sessions to balance accuracy and economic burden, and research into finding this balance would be of considerable value. Third, more accurate measurements can be obtained with $3 \mathrm{D}$ rotational angiography by virtue of the high-resolution and signal-tonoise ratios (61). However, 3D rotational angiography is seldom performed in follow-up imaging because of its high cost and invasiveness. Accordingly, focusing further research on reducing the cost and invasiveness of $3 \mathrm{D}$ rotational angiography, so as to increase its applicability, will greatly increase the reliability of follow-up imaging.

Synthesizing the cluster result of "\#1 Guglielmi detachable coils" and "\#2 stent", we can deduce that "stent" refers to "stent-assisted coil embolization (SACE)", which is the second most popular area of interest. The application of SACE to treat aneurysms has markedly increased following the publication of the results from ISAT $(30,62)$ and the International Study of Unruptured Intracranial Aneurysms (63). Importantly, owing to its better curative effect compared to that of aneurysm clipping $(30,62,63)$, SACE has been performed in more than $50 \%$ patients in need of aneurysm treatment, as reported in European countries in the 1990s, 
in the USA in 2004 (64,65), and in Korea in 2013 (66). Although SACE has been proven to be effective, there is approximately $20 \%$ risk of aneurysm recurrence after SACE treatment, with $9 \%$ of patients requiring retreatment $(67,68)$. Therefore, it is essential to periodically review and identify residual and recurrent aneurysms (69), which is typically done with MRA. Three main types of MRA are used in screening: non-contrast time-of-flight (ncTOF) MRA, contrast-enhanced time-of-flight (cTOF) MRA, and dynamic contrast-enhanced MRA (CEMRA). Initially, ncTOF was used to assess the embolization effect of aneurysms (70-74). Later, cTOF was tested in a few studies and was found to overcome many shortcomings associated with ncTOF (75). However, a consensus has not been reached concerning which of the two has a better comprehensive assessment result (76-78). CEMRA was then introduced to assess the curative effect of SACE (75). CEMRA performs better in the visualization of in-stent signals compared to TOF, and it has been found to have high consistency with DSA for the detection of aneurysms treated by SACE (79). CEMRA is now recommended as the first-line non-invasive imaging screening modality. Therefore, the subject area of "CEMRA\&SACE" should be given more attention. The limitations of the current research listed should provide valuable research direction. First, only 3 studies evaluated distally placed stents with MRA (80-82). The role of MRA in the depiction of aneurysm occlusion and stent visualization in the distal circulation, where small intracranial stents are utilized, remains unknown. Second, coil type is an important influencing factor of susceptibility artifacts, and are likely to have an indirect impact on luminal visibility. Therefore, designing an MRA screening assessment study with a unified coil type can more effectively control bias, which previous studies have failed to manage. Finally, venous contamination and contrast enhancement of the vessel wall can result in false-positive findings with regards to recurrent aneurysms. Aneurysms can be mistaken for residual aneurysm filling due to $\mathrm{T} 1$ shortening (83). These issues may provide a valuable research direction for neuroradiology researchers.

Burst keyword is the keyword co-occurrence analysis function of CiteSpace. The analysis object is the cooccurring author keyword (DE) and keywords plus (ID) fields in the literature, and the result is the burst keyword strength list, which can reflect the main research stream of a given field within a specified period. As shown in Figure 8, "risk factor", "association", and "rupture" were the keywords with the top 3 burst strengths within the past 3 years (5.32,
4.33, and 4.21, respectively). "Risk factors associated to rupture" has been the strongest burst topic since 2017 . Rupture often leads to death or severe disability, and poses a considerable clinical and socioeconomic burden (42). Taking the risk factors of rupture into account when deciding upon treatment and follow-up examinations can enhance the specificity and accuracy of diagnosis and treatment, while at the same time decreasing the redundant examination and the risks posed by aneurysm surgery (84-86). The risk correlation between age and rupture is a question of fundamental importance, with many related published articles (87-91). A descriptive study on 8,144 cases in mainland China conducted by Wáng et al. concluded that elderly patients may be at a reduced risk of rupture compared with younger patients who have other similar risk factors (87). Studies conducted in populations in Finland, the USA, and Japan have also demonstrated that advanced age is a small but significant protective effect for rupture (89-91). A study on 945 Canadian patients with aneurysms by Weir et al. suggested that elderly patients may have reduced risk of rupture compared with patients who are younger with the same-sized aneurysms (88). Collectively, this research indicates that age appears to be inversely related to the risk of rupture, and reflects the importance of MRA follow-up for patients at different ages. As keywords represent the core of an article and the burst keyword reflects the research front $(24,92)$, how MRA can be applied to the follow-up of IA patients to assess the risk of rupture, especially in relatively young patients, would be an important research topic in the IAMRA field.

\section{Study limitations}

The present study has some limitations. First, all the documents were downloaded from the WoS database. As a result, the literature included in this study may not represent the full IAMRA domain. The main reason we choose WoS is that CiteSpace was developed based on the data format of WoS. Data retrieved from the WoS, which includes information on author, institution, country, journal, etc., especially with complete references, are suitable as input data to CiteSpace for ACA and RCA, which could not be performed with the data retrieved from PubMed, Embase, or Ovid databases without complete references. WoS is the most useful database for obtaining global academic information, as it consists of nearly 9,000 of the world's most well-known high-impact research journals. Furthermore, we can obtain complete literature 
information (e.g., author, institution, country, journal) from WoS, convert this information into plain text format, and then input this into CiteSpace for analysis. Second, all the literature analyzed in the present study was in English, which might have led to language bias to some extent. However, we believe that the literature included was representative, as English is the most widely used language in academia. Finally, the MRA performed in an aneurysm after endovascular coiling and the MRA performed in untreated aneurysm are different. The former is more focused on the better visualization under the metal artifact, whereas the latter is more focused on the visualization of a small or irregular shaped aneurysm with complex flow turbulence. We were unable to carry out subcategory analysis or incorporate the differences between these two types of MRA into a more accurate interpretation. This may be a drawback of CiteSpace software when conducting a comprehensive bibliometric analysis in a specific field. Therefore, the results of the data might oversimplify the interpretation of why and how MRA is used for the evaluation of patients with aneurysms. As the present study targeted a large amount of literature, the conceptual trends in the study could be most appropriately interpreted in a broad context, which would provide quantitative evidence for neurointerventionalists searching for the best imaging solutions for patients with aneurysms.

\section{Conclusions}

The IAMRA field has been growing gradually over the past decade. The USA and Western Europe are at the forefront of IAMRA, possessing the greater portion of the leading talent and the high-level scientific research institutions in this field. Currently, the main research areas of interest are unruptured IA growth, SACE, and risk factors associated to rupture, which warrant further research.

\section{Acknowledgments}

The authors would like to thank of all of the study participants.

Funding: This work was supported by Open Project of Guangdong Provincial Key Laboratory of Tropical Disease Research (KLTDR2020003).

\section{Footnote}

Conflicts of Interest: All authors have completed the
ICMJE uniform disclosure form (available at http://dx.doi. org/10.21037/qims-20-729). The authors have no conflicts of interest to declare.

Ethical Statement: All data were obtained through literature retrieval based on the Canonical database. No medical institutions or patients were included, and thus ethical approval or informed consent was not applicable.

Open Access Statement: This is an Open Access article distributed in accordance with the Creative Commons Attribution-NonCommercial-NoDerivs 4.0 International License (CC BY-NC-ND 4.0), which permits the noncommercial replication and distribution of the article with the strict proviso that no changes or edits are made and the original work is properly cited (including links to both the formal publication through the relevant DOI and the license). See: https://creativecommons.org/licenses/by-nc-nd/4.0/.

\section{References}

1. Zhao J, Lin H, Summers R, Yang M, Cousins B, Tsui J. Current Treatment Strategies for Intracranial Aneurysms. Angiology 2018;69:17-30.

2. Vlak MH, Algra A, Brandenburg R, Rinkel G. Prevalence of unruptured intracranial aneurysms, with emphasis on sex, age, comorbidity, country, and time period: A systematic review and meta-analysis. Lancet Neurol 2011;10:626-36.

3. Shipman KE, Ramalingam S, Dawson C, Yasear Z. Subarachnoid haemorrhage. Clin Med (Lond) 2019;19:88-9.

4. Thompson BG, Brown RDJ, Amin-Hanjani S, Broderick JP, Cockroft KM, Connolly ESJ, Duckwiler GR, Harris CC, Howard VJ, Johnston SCC, Meyers PM, Molyneux A, Ogilvy CS, Ringer AJ, Torner J. Guidelines for the Management of Patients With Unruptured Intracranial Aneurysms: A Guideline for Healthcare Professionals From the American Heart Association/American Stroke Association. Stroke 2015;46:2368-400.

5. Toussaint LG, Friedman J, Wijdicks E, Piepgras D, Pichelmann M, McIver J, McClelland R, Nichols D, Meyer F, Atkinson J. Influence of aspirin on outcome following aneurysmal subarachnoid hemorrhage. J Neurosurg 2004;101:921-5.

6. Stegmayr B, Eriksson M, Asplund K. Declining Mortality From Subarachnoid Hemorrhage Changes in Incidence and Case Fatality From 1985 Through 2000. Stroke 2004;35:2059-63. 
7. Taylor TN, Davis P, Torner J, JD H, Meyer J, Jacobson M. Lifetime Cost of Stroke in the United States. Stroke 1996;27:1459-66.

8. Chang SH, Shin H, Lee SH, Ko H, Koh J. Rebleeding of Ruptured Intracranial Aneurysms in the Immediate Postoperative Period after Coil Embolization. J Cerebrovasc Endovasc Neurosurg 2015;17:209-16.

9. Fugate JE, Mallory G, Wijdicks E. Ultra-Early Aneurysmal Rebleeding and Brainstem Destruction. Neurocrit Care 2012;17:439-40.

10. Dawkins AA, Evans AL, Wattam J, Romanowski C, Connolly D, Hodgson T, Coley S. Complications of cerebral angiography: A prospective analysis of 2,924 consecutive procedures. Neuroradiology 2007;49:753-9.

11. Willinsky RA, Taylor S, TerBrugge K, Farb R, Tomlinson G, Montanera W. Neurologic Complications of Cerebral Angiography: Prospective Analysis of 2,899 Procedures and Review of the Literature1. Radiology 2003;227:522-8.

12. Soize S, Gawlitza M, Raoult H, Pierot L. Imaging FollowUp of Intracranial Aneurysms Treated by Endovascular Means: Why, When, and How? Stroke 2016;47:1407-12.

13. Cho YD, Kim K, Lee W, Sohn C-H, Kang H-S, Kim J, Han M. Time-of-Flight Magnetic Resonance Angiography for Follow-Up of Coil Embolization with Enterprise Stent for Intracranial Aneurysm: Usefulness of Source Images. Korean J Radiol 2014;15:161-8.

14. Cho W-S, Kim S, Lee SJ, Kim S. The effectiveness of 3T time-of-flight magnetic resonance angiography for followup evaluations after the stent-assisted coil embolization of cerebral aneurysms. Acta Radiol 2014;55:604-13.

15. P. Pearse Morris. Practical Neuroangiography. 2014.

16. van Amerongen MJ, Boogaarts J, Vries J, Verbeek A, Meijer F, Prokop M, Bartels R. MRA Versus DSA for Follow-Up of Coiled Intracranial Aneurysms: A MetaAnalysis. AJNR Am J Neuroradiol 2014;35:1655-61.

17. Menke J, Schramm P, Sommerlath Sohns J, Kallenberg $\mathrm{K}$, Staab W. Diagnosing flow residuals in coiled cerebral aneurysms by MR angiography: Meta-analysis. J Neurol 2014;261:655-62.

18. Ahmed SU, Mocco J, Zhang X, Kelly M, Doshi A, Nael K, De Leacy R. MRA versus DSA for the follow-up imaging of intracranial aneurysms treated using endovascular techniques: A meta-analysis. J Neurointerv Surg 2019;11:1009-14.

19. Schaafsma JD, Koffijberg H, Buskens E, Velthuis B, Graaf Y, Rinkel G. Cost-Effectiveness of Magnetic Resonance Angiography Versus Intra-arterial Digital Subtraction Angiography to Follow-Up Patients With Coiled
Intracranial Aneurysms. Stroke 2010;41:1736-42.

20. Chen C. CiteSpace II: Detecting and visualizing emerging trends and transient patterns in scientific literature. J Am Soc Inf Sci Technol 2006;57:359-77.

21. Chen C, Ibekwe-Sanjuan F, Hou J. The Structure and Dynamics of Co-Citation Clusters: A Multiple-Perspective Co-Citation Analysis. J Am Soc Inf Sci Technol 2010;61:1386-409.

22. Yang DW, Wang X, Wang Z, Yang Z, Bian X. A scientometric analysis on hepatocellular carcinoma magnetic resonance imaging research from 2008 to 2017. Quant Imaging Med Surg 2019;9:465-76.

23. Lee Y, Chen C, Tsai X. Visualizing the Knowledge Domain of Nanoparticle Drug Delivery Technologies: A Scientometric Review. Appl Sci 2016;6:11.

24. Liang YD, Li Y, Zhao J, Wang X, Zhu H, Chen X. Study of acupuncture for low back pain in recent 20 years: A bibliometric analysis via CiteSpace. J Pain Res 2017;10:951-64.

25. Zongyi Y, Dongying C, Baifeng L. Global Regulatory T-Cell Research from 2000 to 2015: A Bibliometric Analysis. PLoS One 2016;11:e162099.

26. Xiao F, Li C, Sun J, Zhang L. Knowledge Domain and Emerging Trends in Organic Photovoltaic Technology: A Scientometric Review Based on CiteSpace Analysis. Front Chem 2017;5:67.

27. Miao Y, Liu R, Pu Y, Yin L. Trends in esophageal and esophagogastric junction cancer research from 2007 to 2016. Medicine (Baltimore) 2017;96:e6924.

28. Kreiser K, Gehling K, Zimmer C. Simulation in Angiography - Experiences from 5 Years Teaching, Training, and Research. Rofo 2019;191:547-52.

29. Baker HL. Neuroradiology at the Mayo Clinic. Mayo Clin Proc 1995;70:1221.

30. Molyneux A, Kerr R, Stratton I, Sandercock P, Clarke M, Shrimpton J, Holman R. International Subarachnoid Aneurysm Trial (ISAT) of neurosurgical clipping versus endovascular coiling in 2143 patients with ruptured intracranial aneurysms: A randomised trial. Lancet 2002;360:1267-74.

31. Malhotra A, Wu X. Growth and Rupture Risk of Small Unruptured Intracranial Aneurysms. Ann Intern Med 2018;168:159.

32. Cornelissen BM, Schneiders J, Potters W, Berg R, Velthuis B, Rinkel G, Slump C, Vanbavel E, Majoie C, Marquering H. Hemodynamic Differences in Intracranial Aneurysms before and after Rupture. AJNR Am J Neuroradiol 2015;36:1927-33. 
33. Mocco J, Brown R, Torner J, Capuano A, Fargen K, Raghavan M, Piepgras D, Meissner I, Huston J. Aneurysm Morphology and Prediction of Rupture: An International Study of Unruptured Intracranial Aneurysms Analysis. Neurosurgery 2018;82:491-96.

34. Trujillo CM, Long T. Document co-citation analysis to enhance transdisciplinary research. Sci Adv 2018;4:e1701130.

35. Etminan N, Rinkel G. Unruptured intracranial aneurysms: development, rupture and preventive management. Nat Rev Neurol 2016;12:699-713.

36. Villablanca JP, Duckwiler GR, Jahan R, Tateshima S, Martin NA, Frazee J, Gonzalez NR, Sayre J, Vinuela F V. Natural history of asymptomatic unruptured cerebral aneurysms evaluated at CT angiography: growth and rupture incidence and correlation with epidemiologic risk factors. Radiology 2013;269:258-65.

37. Juvela S, Poussa K, Lehto H, Porras M. Natural History of Unruptured Intracranial Aneurysms A Long-term Followup Study. Stroke 2013;44:2414-21.

38. Matsumoto K, Akagi K, Abekura M, Nakajima Y, Yoshiminie T. Investigation of the surgically treated and untreated unruptured cerebral aneurysms of the anterior circulation. Surg Neurol 2003;60:516-22.

39. Morita A, Fujiwara S, Hashi K, Ohtsu H, Kirino T. Risk of rupture associated with intact cerebral aneurysms in the Japanese population: a systematic review of the literature from Japan. J Neurosurg 2005;102:601-6.

40. Rinkel GJ, Djibuti M, Algra A, Gijn J. Prevalence and Risk of Rupture of Intracranial Aneurysms : A Systematic Review. Stroke 1998;29:251-6.

41. Aneurysms TIS of UI, Investigators. Unruptured intracranial aneurysms--risk of rupture and risks of surgical intervention. N Engl J Med 1998;339:1725-33.

42. Guha D, Ibrahim G, Kertzer J. National socioeconomic indicators are associated with outcomes after aneurysmal subarachnoid hemorrhage: a hierarchical mixed-effects analysis. J Neurosurg 2014;121:1039-47.

43. Jin D, Song C, Leng X, Han P. A systematic review and meta-analysis of risk factors for unruptured intracranial aneurysm growth. Int J Surg 2019;69:68-76.

44. Slot EM, Rinkel G, Algra A, Ruigrok Y. Patient and aneurysm characteristics in familial intracranial aneurysms. A systematic review and meta-analysis. PLoS One 2019; 14:e0213372.

45. Matsumoto K, Oshino S, Manabu S, Tsuruzono K, Taketsuna S, Yoshimine T. Incidence of growth and rupture of unruptured intracranial aneurysms followed by serial MRA. Acta Neurochir (Wien) 2013;155:211-6.

46. Roi DP, Mueller J-D, Lobotesis K, McCague C, Memarian S, Khan F, Mankad K. Intracranial aneurysms: looking beyond size in neuroimaging: the role of anatomical factors and haemodynamics. Quant Imaging Med Surg 2019;9:537-45.

47. Backes D, Vergouwen M, Groenestege A, Bor A, Velthuis B, Greving J, Algra A, Wermer M, Walderveen M, terBrugge K, Agid R, Rinkel G. PHASES Score for Prediction of Intracranial Aneurysm Growth. Stroke 2015;46:1221-6.

48. Backes D, Rinkel G, Greving J, Velthuis B, Murayama Y, Takao H, Ishibashi T, Igase M, terBrugge K, Agid R, Jääskeläinen J, Lindgren A, Koivisto T, Fraunberg M, Matsubara S, Moroi J, Wong G, Abrigo J, Igase K, Vergouwen M. ELAPSS score for prediction of risk of growth of unruptured intracranial aneurysms. Neurology 2017;88:1600-6.

49. Björkman J, Tähtinen O, Huttunen T, Huttunen J, Kurki M, Koivisto T, Manninen H, Jääskeläinen J, Lindgren A. Aneurysm size is the strongest predictor of intracranial aneurysm growth in Eastern Finnish population. Neurosurgery 2019;84:1098-103.

50. Brinjikji W, Pereira V, Khumtong R, Kostensky A, Tymianski M, Krings T, Radovanovich I. PHASES and ELAPSS score are associated with aneurysm growth: A study of 431 unruptured intracranial aneurysms. World Neurosurg 2018;114:e425-32.

51. Burns JD, Huston J, Layton K, Piepgras D, Brown R. Intracranial Aneurysm Enlargement on Serial Magnetic Resonance Angiography Frequency and Risk Factors. Stroke 2009;40:406-11.

52. Choi HH, Cho YD, Jeon JP, Yoo DH, Moon J, Lee J, Kang H-S, Cho W-S, Kim JE, Zhang L, Han MH. Growth of Untreated Unruptured Small-sized Aneurysms (<7mm): Incidence and Related Factors. Clin Neuroradiol 2018;28:183-9.

53. Ferns SP, Sprengers M, van Rooij WJ, Berg R, Velthuis B, Kort G, Sluzewski M, Zwam W, Rinkel G, Majoie C. De Novo Aneurysm Formation and Growth of Untreated Aneurysms A 5-Year MRA Follow-Up in a Large Cohort of Patients With Coiled Aneurysms and Review of the Literature. Stroke 2011;42:313-8.

54. Igase M, Igase K, Kohara K, Yamashita S, Fujisawa M, Katagi R, Miki T. Visit-To-Visit Variability in Systolic Blood Pressure Is a Novel Risk Factor for the Growth of Intracranial Aneurysms. Cerebrovasc Dis 2013;36:401-6. 55. Juvela S. Growth and rupture of unruptured intracranial 
aneurysms. J Neurosurg 2018;131:843-51.

56. Inoue T, Shimizu H, Fujimura M, Saito A, Tominaga T. Annual rupture risk of growing unruptured cerebral aneurysms detected by magnetic resonance angiography Clinical article. J Neurosurg 2012;117:20-5.

57. Jeon JS, Ahn J, Huh W, Son YJ, Bang J, Kang HS, Sohn $\mathrm{CH}$, Oh C, Kwon OK, Kim J. A retrospective analysis on the natural history of incidental small paraclinoid unruptured aneurysm. J Neurol Neurosurg Psychiatry 2014;85:289-94.

58. Kubo Y, Koji T, Kashimura H, Otawara Y, Ogawa A, Ogasawara $\mathrm{K}$. Female sex as a risk factor for the growth of asymptomatic unruptured cerebral saccular aneurysms in elderly patients Clinical article. J Neurosurg 2014;121:599-604.

59. Miyazawa N, Akiyama I, Yamagata Z. Risk factors for growth of unruptured intracranial aneurysms: follow-up study by serial 0.5-T magnetic resonance angiography. Neurosurgery 2006;58:1047-53.

60. Moon J, Cho Y, Yoo D, Lee J, Kang HS, Cho WS, Kim J, Zhang L, Han M. Growth of Asymptomatic Intracranial Fusiform Aneurysms: Incidence and Risk Factors. Clin Neuroradiol 2019;29: 717-23.

61. Ajam A, Aziz A, Asirvadam V, Muda S, Faye I, Gardezi J. A Review on Segmentation and Modeling of Cerebral Vasculature for Surgical Planning. IEEE Access 2017;5:15222-40.

62. Molyneux AJ, Kerr R, Yu LM, Clarke M, Sneade M, Yarnold J, Sandercock P. International subarachnoid aneurysm trial (ISAT) of neurosurgical clipping versus endovascular coiling in 2143 patients with ruptured intracranial aneurysms: a randomised comparison of effects on survival, dependency, seizures, rebleeding, subgroups, and aneurysm occlusion. Lancet 2005;366:809-17.

63. Wiebers DO, Whisnant J, Huston J, Meissner I, Brown R, Piepgras D, Forbes G, Thielen K, Nichols D, O'Fallon W, Peacock J, Jaeger L, Kassell N, Kongable G, Torner J. Unruptured intracranial aneurysms: Natural history, clinical outcome, and risks of surgical and endovascular treatment. Lancet 2003;362:103-10.

64. Huang MC, Baaj A, Downes K, Youssef A, Sauvageau E, Loveren H, Agazzi S. Paradoxical Trends in the Management of Unruptured Cerebral Aneurysms in the United States Analysis of Nationwide Database Over a 10Year Period. Stroke 2011;42:1730-5.

65. Alshekhlee A, Mehta S, Edgell R, Vora N, Feen E, Mohammadi A, Kale S, Cruz-Flores S. Hospital Mortality and Complications of Electively Clipped or Coiled Unruptured Intracranial Aneurysm. Stroke 2010;41:1471-6.
66. Chang HW, Shin S, Suh SH, Kim B, Rho M. CostEffectiveness Analysis of Endovascular Coiling versus Neurosurgical Clipping for Intracranial Aneurysms in Republic of Korea. Neurointervention 2016;11:86-91.

67. Crobeddu E, Lanzino G, Kallmes D, Cloft H. Review of 2 Decades of Aneurysm-Recurrence Literature, Part 1: Reducing Recurrence after Endovascular Coiling. AJNR Am J Neuroradiol 2013;34:266-70.

68. Crobeddu E, Lanzino G, Kallmes D, Cloft H. Review of 2 Decades of Aneurysm-Recurrence Literature, Part 2: Managing Recurrence after Endovascular Coiling. AJNR Am J Neuroradiol 2013;34:481-5.

69. Ferns SP, Sprengers M, van Rooij WJ, Rinkel G, Rijn J, Bipat S, Sluzewski M, Majoie C. Coiling of Intracranial Aneurysms A Systematic Review on Initial Occlusion and Reopening and Retreatment Rates. Stroke 2009;40:e523-9.

70. Derdeyn CP, Graves V, Turski P, Masaryk A, Strother C. MR angiography of saccular aneurysms after treatment with Guglielmi detachable coils: Preliminary experience. AJNR Am J Neuroradiol 1997;18:279-86.

71. Kähärä VJ, Seppänen S, Ryymin P, Mattila P, Kuurne T, Laasonen E. MR Angiography with Three-Dimensional Time-of-Flight and Targeted Maximum-Intensity-Projection Reconstructions in the Follow-up of Intracranial Aneurysms Embolized with Guglielmi Detachable Coils. AJNR Am J Neuroradiol 1999;20:1470-5.

72. Wong JH, Mitha AP, Willson M, Hudon ME, Sevick RJ, Frayne R. Assessment of brain aneurysms by using high-resolution magnetic resonance angiography after endovascular coil delivery. J Neurosurg 2007;107:283-9.

73. Urbach H, Dorenbeck U, Falkenhausen M, Wilhelm K, Md W, Schaller C, Flacke S. Three-dimensional timeof-flight MR angiography at $3 \mathrm{~T}$ compared to digital subtraction angiography in the follow-up of ruptured and coiled intracranial aneurysms: A prospective study. Neuroradiology 2008;50:383-9.

74. Ferré J-C, Carsin-Nicol B, Morandi X, Carsin M, Kersaint-Gilly A, Gauvrit jean-yves, Desal H. Time-offlight MR angiography at $3 \mathrm{~T}$ versus digital subtraction angiography in the imaging follow-up of 51 intracranial aneurysms treated with coils. Eur J Radiol 2009;72:365-9.

75. Anzalone N, Righi C, Simionato F, Scomazzoni F, Pagani G, Calori G, Santino P, Scotti G. Three-dimensional timeof-flight MR angiography in the evaluation of intracranial aneurysms treated with Guglielmi detachable coils. AJNR Am J Neuroradiol 2000;21:746-52.

76. Cottier J-P, Bleuzen-Couthon A, Gallas S, Vinikoff-Sonier C, Bertrand P, Domengie F, Barantin L, Herbreteau 
D. Intracranial Aneurysms Treated with Guglielmi Detachable Coils: Is Contrast Material Necessary in the Follow-up with 3D Time-of-Flight MR Angiography? AJNR Am J Neuroradiol 2003;24:1797-803.

77. Kwee TC, Kwee R. MR angiography in the follow-up of intracranial aneurysms treated with Guglielmi detachable coils: Systematic review and meta-analysis. Neuroradiology 2007;49:703-13.

78. Wikström J, Ronne Engström E, Gál G, Enblad P, Tovi M. Three-Dimensional Time-of-Flight (3D TOF) Magnetic Resonance Angiography (MRA) and Contrast-Enhanced MRA of Intracranial Aneurysms Treated with Platinum Coils. Acta Radiol 2008;49:190-6.

79. Akkaya S, Akca O, Arat A, Peker A, Balci S. Usefulness of contrast-enhanced and TOF MR angiography for followup after low-profile stent-assisted coil embolization of intracranial aneurysms. Interv Neuroradiol 2018;24:655-61.

80. Brassel F, Grieb D, Meila D, Schlunz-Hendann M, Greling B, Melber K. Endovascular treatment of complex intracranial aneurysms using Acandis Acclino stents. J Neurointerv Surg 2017;9:854-9.

81. Shankar JJ, Quateen A, Weill A, Tampieri D, Cortes M, Fahed R, Patro S, Kaderali Z, Lum C, Lesiuk H, Ahmed U, Peeling L, Kelly M, Iancu D. Canadian Registry of LVIS Jr for Treatment of Intracranial Aneurysms (CaRLA). J Neurointerv Surg 2017;9:849-53.

82. Aydin K, Arat A, Sencer S, Barburoglu M, Men S. StentAssisted Coiling of Wide-Neck Intracranial Aneurysms Using Low-Profile LEO Baby Stents: Initial and Midterm Results. AJNR Am J Neuroradiol 2015;36:1934-41.

83. Choi JW, Roh H, Moon WJ, Kim N, Moon S, Kang CH, Chun Y, Kang HS. Time-Resolved 3D Contrast-Enhanced MRA on 3.0T: a Non-Invasive Follow-Up Technique after Stent-Assisted Coil Embolization of the Intracranial Aneurysm. Korean J Radiol 2011;12:662-70.

84. Lecler A, Raymond J, Rodriguez R, Al S, Trystram D, Godon H, Ben H, Meder J, Oppenheim C, Naggara O. Intracranial Aneurysms: Recurrences More than 10 Years after Endovascular Treatment-A Prospective Cohort Study, Systematic Review, and Meta-Analysis. Radiology 2015;277:173-80.

85. Wáng YX, He J, Zhang L, Li Y, Zhao L, Liu H, Yang L, Zeng XJ, Yang J, Peng GM, Ahuja A, Yang ZH. A higher aneurysmal subarachnoid hemorrhage incidence in women prior to menopause: a retrospective analysis of 4,895 cases from eight hospitals in China. Quant Imaging Med Surg 2016;6:151-6.

86. Molyneux AJ, Birks J, Clarke A, Sneade M, Kerr R. The durability of endovascular coiling versus neurosurgical clipping of ruptured cerebral aneurysms: 18 year followup of the UK cohort of the International Subarachnoid Aneurysm Trial (ISAT). Lancet 2015;385:691-7.

87. Wáng YX, Zhang L, Zhao L, He J, Zeng X, Liu H, Yang Y, Ding S, Xu Z, He Y, Yang L, Sun L, Mu K, Wang B, Xu X, Ji Z, Liu J, Fang J, Hou R, Fan F, Peng G, Zhu Y, Ju S, Poon W. Elderly population have a decreased aneurysmal subarachnoid hemorrhage incidence rate than Middle aged population: a descriptive analysis of 8,144 cases in mainland China. Br J Neurosurg 2018;32:165-71.

88. Weir B, Disney L, Karrison T. Sizes of ruptured and unruptured aneurysms in relation to their sites and the ages of patients. J. Neurosurg 2002;96:64-70.

89. Taylor CL, Yuan Z, Selman W, Ratcheson R, Rimm A. Cerebral arterial aneurysm formation and rupture in 20,767 elderly patients: hypertension and other risk factors. J Neurosurg 1995;83:812-9.

90. Yasui N, Suzuki A, Nishimura H, Suzuki K, Abe T. Long-term follow-up study of unruptured intracranial aneurysms. Neurosurgery 1997;40:1155-9.

91. Juvela S, Porras M, Poussa K. Natural history of unruptured intracranial aneurysms: probability of and risk factors for aneurysm rupture. J Neurosurg 2008;108:1052-60.

92. Xie P. Study of international anticancer research trends via co-word and document co-citation visualization analysis. Entometrics 2015;105:611-22.
Cite this article as: Zheng J, Zhou R, Meng B, Li F, Liu $\mathrm{H}, \mathrm{Wu} \mathrm{X}$. Knowledge framework and emerging trends in intracranial aneurysm magnetic resonance angiography: a scientometric analysis from 2004 to 2020. Quant Imaging Med Surg 2021;11(5):1854-1869. doi: 10.21037/qims-20-729 